\title{
Student Evaluations of Instructor Email Response Speed as Chronemic Expectancy Violations
}

\author{
Nicholas T. Tatum \\ University of Nevada, Las Vegas
}

\begin{abstract}
Instructional communication researchers have begun exploring the effects of email response speed on student evaluations of their instructors. To date, researchers have concluded that faster response times result in more favorable evaluations. To extend this line of research, this experiment explores student evaluations of instructor response speed through the lens of expectancy violations theory, arguing that eliciting positive evaluations is not just about responding quickly, but rather, responding more quickly than students expect. Results indicated that positive violations of instructor email response speed are evaluated more favorably than negative chronemic violations in terms of instructor credibility and relational closeness. These findings contribute practical implications for instructors inundated with email exchanges with students and offer theoretical nuance to the study of chronemics in instructor-student email communication.
\end{abstract}

Keywords: email, response speed, chronemics, credibility, instructor-student relationship

Email has become, and is likely to remain, a predominant text-based computermediated communication (CMC) channel in the instructional process (Chang et al., 2016; Conklin \& Dikkers, 2021). Even in face-toface (F2F) classes, there is an increase in students opting to use mediated channels like email to communicate with their instructors (Brooks \& Young, 2016; Duran et al., 2005;
Stephens et al., 2009). Accordingly, email is a central communication channel for instructors and students and should be of interest to instructional communication researchers (Bolkan \& Holmgren, 2012; Sheer \& Fung, 2007; Young et al., 2011).

Text-based CMC, like email, lacks nonverbal components allowed by traditional 
F2F interactions in the classroom (e.g., tone of voice, facial expressions, vocal pitch; Stafford \& Hillyer, 2012; Walther, 2011). In the absence of these nonverbal cues, communicators (i.e., students) place greater focus on elements that remain (e.g., word choice, communication channel; see social information processing theory; Walter 1992, 1994). Across contexts, one cue that has evidenced importance is the speed at which an individual responds to $\mathrm{CMC}$ messages (i.e., chronemics). Quicker CMC response speeds have been associated with more favorable evaluations in customer-service (Jiang et al., 2002), virtual communities (Ridings et al., 2002; Zimmerman \& Zimmerman, 2016), and even interpersonal relationships (Walther \& Tidwell, 1995). Like other contexts, students generally desire quick replies to their email messages in both F2F and online courses (Argon, 2003; Foral et al., 2010; Johnson \& Card, 2007). In fact, it seems like students view email as "a form of telepathythe instantaneous communication of an uncensored thought, often with the expectation of an immediate response" (Weinstock, 2004, p. 380).

But, how fast is fast enough? Chang et al. (2016) claimed students viewed any response within 24 hours as acceptable. In fact, many instructors seem to abide by a 24-hour response rule in their classrooms (Leidman \& Piwinsky, 2009; Pate et al., 2021), whether or not there was an explicit policy included in the course syllabus (Curtis et al., 2013). However, students may enter the classroom with varying expectations about how quickly their instructor should respond to their email messages (Tatum et al., 2018). What one student could view as a prompt response may be perceived as overdue by another. In this way, if instructors hope to elicit positive chronemic evaluations from their students, perhaps it is more important for instructors to respond to student emails quicker than expected rather than simply responding to emails quickly. This study seeks to explore this idea by framing student evaluations of instructor email response speeds as expectancy violations. To begin, an overview of expectancy violations theory (Burgoon \& Jones, 1976) provides a theoretical lens through which to understand student evaluations of instructor email response speeds. Then, student perceptions of instructors that could be affected as a result of violated chronemic expectations (i.e., credibility and relational closeness) are forwarded.

\section{Expectancy Violations Theory}

Expectancy violations theory (EVT; Burgoon \& Jones, 1976) defines expectations as consistent patterns of predictable behavior for a relationship, context, or individual (Burgoon, 1993). Initially, the theory was developed to explore expectations of personal space in interpersonal interactions (i.e., proxemics), but its application has since been expanded to explain other forms of nonverbal communication such as chronemics. EVT has been used to understand communication in CMC contexts such as modality switching (Jin, 2012; Ramirez \& Wang, 2008) and interactions on Facebook (Bevan et al., 2014; McLaughlin \& Vitak, 2012).

Expectations are violated when another person behaves in a way that is not anticipated or typical (Afifi \& Metts, 1998). Positive violations occur when expectations are exceeded (i.e., an instructor responds to an email quicker than expected), and negative violations occur when expectations are not met (i.e., an instructor responds to an email slower than expected). An expectancy confirmation occurs when expectations are matched or 
fulfilled (i.e., an instructor responds to an email at the anticipated time). EVT posits that when violations occur, heightened attention is first given to the aspect of the interaction that deviates from expectations (i.e., instructor's response time). Then, individuals process the violation through a process of interpretation and evaluation, subsequently making judgements about the source of the violation (i.e., the instructor; Burgoon \& Hale, 1988). Positive violations elicit more favorable evaluations of the source than negative violations, and negative violations elicit less favorable evaluations of the source than positive violations (Burgoon, 1993; Johnson, 2012; Johnson \& Lewis, 2010). Kalman and Rafaeli (2011) provided initial support for the extension of EVT to the study of email chronemics, concluding that in the business context, quicker replies (i.e., one day) are generally viewed as more expected and elicit more favorable evaluations than slower replies (i.e., two or more weeks).

Researchers have only recently begun using EVT to understand student response speed evaluations of instructor emails. Martin and Tatum (2017) found that quicker response times (i.e., 10 hours) resulted in higher levels of instructor liking than slower response times (i.e., 14 days), arguing that these differences were a result of violations of student chronemics expectations. Expanding on these findings, Tatum et al. (2018) found the quicker an instructor responds to a student email, the more positively they are evaluated in terms of attraction and credibility. Like Martin and Tatum (2017), this study employed EVT as a theoretical framework for anticipating and understanding student evaluations. While important for forwarding the field's knowledge of chronemics in instructorstudent email communication, neither study actually provided a test of EVT; both only compared evaluations of response time rather than evaluations resulting from violations of student chronemic expectations. Thus, to further this line of research, the present study seeks to compare student evaluations resulting from positive chronemic violations and negative chronemic violations. Specifically, evaluations of instructor credibility and relational closeness are considered.

\section{Credibility}

Credibility, conceptualized as a communication source's believability (Frymier \& Thompson, 1992; McCroskey \& Young, 1981), comprises three dimensions (McCroskey \& Teven, 1999): competence (i.e., expertise or knowledge), character (i.e., trustworthiness), and caring (i.e., concern with student well-being). Credible instructors are generally perceived as more understanding (Schrodt, 2003), immediate (Teven, 2001), and just (Chory, 2007), receiving high course evaluations from students (Teven \& McCroskey, 1997). Existing chronemics research links slower (faster) email response speeds to lower (higher) perceptions of credibility (Kalman \& Rafaeli, 2011; Tatum et al., 2018). Given these findings and the logic proposed by EVT, it seems expected that positive chronemics violations of instructor email response speed will result in higher evaluations of instructor competence, character, and caring than negative chronemic violations:

H1: Positive chronemic violations will result in higher evaluations of instructor credibility - (a) competence, (b) character, and (c) caring - than negative chronemic violations.

\section{Relational Closeness}

In addition to influencing perceptions 
of credibility, evaluations of instructor response speed could influence student perceptions of the closeness of their instructorstudent relationship. Relational closeness is conceptualized as a "subjective experience of intimacy, emotional affinity, and psychological bonding with another person" (Ledbetter et al., 2010, p. 8). The instructor-student bond is inherently relational (Mottet et al., 2006), and maintaining a close instructorstudent relationship has measured benefits for students (Claus et al., 2012; Tatum, 2021). It seems likely that a students' evaluation of their instructor's email response speed could influence their perceptions of relational closeness. Walther and Tidwell (1995) found that slower email messages are perceived as less intimate than quicker messages. In this way, email response speed can serve as a cue for perceptions of immediacy (Ledbetter, 2008). Perhaps responding more quickly to email messages makes instructors seem more responsive, and these perceptions of responsiveness lead to feelings of relational closeness (Reis et al., 2004). As such, framed by EVT, it seems probable that positive chronemic violations of instructor email response speed will result in higher evaluations of relational closeness than negative chronemic violations:

H2: Positive chronemic violations will result in greater perceptions of relational closeness than negative chronemic violations.

\section{Method}

\section{Sampling Procedure and Research Design}

Upon receiving institutional review board approval, participants were recruited from a large southern university through a research participation system during the last three weeks of the Fall semester (preCOVID-19). Students electing to participate received minimal course credit. Participants were randomly assigned to view a vignette in the form of a hypothetical email exchange between themselves and an instructor of an unknown gender from a F2F class. The brief, cordial exchange consisted of an initial email from the student asking to meet with the instructor for clarification about a daily grade assignment, followed by an instructor response agreeing to a meeting (See Appendix 1). To hold constant other factors that may influence chronemic perceptions (Walther \& Tidwell, 1995), metadata were not included with either message (i.e., subject lines, email addresses, timestamps, dates). Conditions were identical apart from a statement between the student's initial message and the instructor's response that read, "After sending the above email, you receive the following email response from your instructor $\mathrm{X}$ hour(s) after you sent the initial email."

Given the prevalence of 24-hour email policies in university classrooms (Curtis et al., 2013), manipulated email response speeds ranged from zero hours to 24 hours. However, because it seemed unlikely that an instructor would respond to an email instantaneously (i.e., zero hours), the zero-hour condition was instead manipulated as ten minutes. Response times were manipulated in four-hour increments (i.e., 7 conditions) to maintain a robust number of participants in each condition based on the anticipated sample size while still promoting variety among potential violation perceptions. Using a single openended question, a manipulation check was conducted by asking participants to recall how long it took the instructor to respond to their message ("How long did it take the instructor to reply to the hypothetical email?"). Those failing to recall the correct time were 
excluded from analysis $(n=61)$; these excluded participants appeared to be random across chronemic conditions. In the end, each condition had at least 60 participants, with an average of 72 participants per condition.

For hypothesis testing, a simple formula was used to operationalize violation valence (i.e., positive violation or negative violation). At the start of the survey, prior to viewing their assigned condition, participants were asked how long they typically expect their F2F instructors to take when responding to email messages using a single open-ended question ("How long do you typically expect an instructor from a face-to-face class to take when responding to an email message?"; $M=$ 7.50 hours, $S D=7.33$ hours). Then, the time it took the hypothetical instructor to respond in the assigned condition was subtracted from the participant's expected response speed (Expected Response Time - Response Time in Condition; $M=-4.95$ hours; $S D$ $=10.64)$. Negative chronemic violations occurred most frequently $(n=330 ; 65 \%)$, wherein the instructor responded slower than expected. These negative violations ranged from -1 to -36 hours $(M=-8.60$ hours, $S D$ $=7.32)$. Positive chronemic violations were less common ( $n=136 ; 26.7 \%)$, wherein the instructor responded quicker than expected. These positive violations ranged from 1 to 23 hours $(M=11.14$ hours, $S D=5.94)$. Participant expectations were considered confirmed when values equaled zero and were not included in data analysis for the present study $(n=42 ; 8.3 \%)$.

\section{Participants}

Participants $(N=508)$ identified as female $(n=348 ; 68.4 \%)$ and male $(n=160$; $31.4 \%$ ). Reported ages ranged from 18 to 31 $(M=18.54, S D=1.23)$. Students identified as Caucasian $(n=417 ; 81.9 \%)$, African American $(n=38 ; 7.5 \%)$, Asian $(n=22$; $4.3 \%)$, Hispanic $(n=11 ; 2.2 \%)$, American Indian or Alaska Native $(n=3 ; .6 \%)$, and other $(n=17 ; 3.3 \%)$. The sample encompassed 34 unique majors across the university and included various student classifications: first year $(n=440 ; 86.4 \%)$, sophomore $(n=55$; $10.8 \%)$, junior $(n=12 ; 2.4 \%)$, and senior $(n$ $=1 ; .2 \%)$. Compared to other communication channels, on a scale from very unlikely (1) to very likely (5), students communicated most frequently via email $(M=4.18, S D=.77)$. They also reported communicating in person before or after class $(M=3.83, S D=1.01)$, through a learning management system $(M=$ 3.66, $S D=1.06)$, during office hours $(M=$ $3.51, S D=.99)$, via text message $(M=1.55$, $S D=.91)$, on the phone $(M=1.50, S D=.78)$, through social media $(M=1.43, S D=.79)$, and through video chat $(M=1.37, S D=.74)$.

\section{Instrumentation}

Instructor credibility. The three dimensions of instructor credibility were operationalized using a combination of two measures (Finn \& Ledbetter, 2013), both of which employ semantic differential items with contrasting adjectives placed at opposite ends of a 7-point scale. Instructor caring was measured using Teven and McCroskey's (1997) Caring Scale ( $n=9$; e.g., "Cares about me - Doesn't care about me"). McCroskey and Young's (1981) Teacher Credibility Scale was used to measure instructor competence ( $n=6$; e.g., "Intelligent - Unintelligent") and character ( $n=6$; e.g., "Untrustworthy - Trustworthy"). All three dimensions demonstrated acceptable reliability in the current study: competence $(M=5.66, S D=$ $1.09 ; \alpha=.93)$, character $(M=5.48, S D=1.12$; $\alpha=.92)$, and caring $(M=5.29, S D=1.14 ; \alpha=$ $.95)$. 
Relational closeness. Relational closeness was operationalized using Mottet's (2000) Relational Closeness Scale. This 5-item instrument (e.g., "Close - Distant") asks students to assess their perceived relationship with their instructor with contrasting adjectives placed at opposite ends of a 7-point scale. The scale was reliable in the current study $(M=5.22, S D=1.09 ; \alpha=.90)$.

\section{Results}

H1 predicted that positive chronemic violations would result in higher evaluations of instructor (a) competence, (b) character, and (c) caring than negative chronemic violations. For H1a, an independent samples t-test revealed that positive violations $(M$ $=6.03, S D=.90)$ resulted in significantly higher evaluations of instructor competence than negative violations $(M=5.47, S D=$ 1.13) $[t(313.44)=-5.72, p<.001$, Hedges' $g=0.53]$. For H1b, an independent samples t-test revealed that positive violations ( $M$ $=5.89, S D=.92$ ) resulted in significantly higher evaluations of instructor character than negative violations $(M=5.26, S D=$ 1.15) $[t(313.05)=-6.21, p<.001$, Hedges' $g=0.58]$. For H1c, an independent samples t-test revealed that positive violations $(M=$ $5.85, S D=.89$ ) resulted in significantly higher evaluations of instructor caring than negative violations $(M=5.00, S D=1.15)[t(321.44)$ $=-8.59, p<.001$, Hedges' $g=0.79]$. H1 was supported.

$\mathrm{H} 2$ predicted that positive chronemic violations would result in greater perceptions of relational closeness than negative chronemic violations. An independent samples t-test revealed that positive violations ( $M$ $=5.71, S D=.94$ ) resulted in significantly higher evaluations of relational closeness than negative violations $(M=4.98, S D=1.09)$ $[t(289.87)=-7.25, p<.001$, Hedges' $g=0.69]$. $\mathrm{H} 2$ was supported.

\section{Discussion}

Instructor inboxes are flooded with student messages each day as email remains a primary communication channel for students enrolled in F2F courses. Theoretically, while other studies have used EVT as a framework for understanding the role of chronemics, this is the first to compare positive violations and negative violations of email response speed. Results from this study provide additional evidence that EVT is an appropriate framework for understanding student chronemic expectations for email communication. Instructors who positively violate student email response speed expectations are evaluated more highly in terms of competence, character, caring, and relational closeness than those who negatively violate student chronemic expectations. These findings theoretically extend what is known about student evaluations of instructor response speed and offer practical implications for instructors.

This study's findings run counter to Chang et al. (2016) who suggested students viewed any response within 24 hours as acceptable. In fact, according to this sample, on average, students expected their instructors to respond in less than 7.5 hours. While there was variability in these expectations $(S D=7.33$ hours), even if instructors respond to messages within 24 hours - a metric that seems to be common among university educators (Curtis et al., 2013) - students may still be dissatisfied. These descriptive results provide initial evidence that students' chronemic expectations for instructors are rapidly changing. For instructors inundated with teaching, service, and/or scholarship, responding within this 
narrowing window may prove impossible. And, simply because students expect a response within a particular time period does not mean instructors should bend to students' seemingly unfeasible chronemic desires. Burgoon and Walther (1990) noted that expectations are derived from the context of the interaction (e.g., the university classroom), relational history with the source of the violation (e.g., past interactions with the instructor), characteristics of the source (e.g., the instructor's personality and communication style), and the source's group membership (e.g., instructors in general). So, a conversation at the beginning of a course where instructors communicate with their students about their expectations for response speed has potential to alter students' seemingly synchronous presumptions for this $\mathrm{CmC}$ channel (Martin \& Tatum, 2017). This adjustment could unburden instructors from feeling obligated to respond immediately and cause students to have more realistic expectations of their instructor's responsiveness.

Importantly, previous research exploring response latency has almost exclusively been concerned with organizational contexts (e.g., corporations; Kalman \& Rafaeli, 2011; Kalman et al., 2013; Walther \& Tidwell, 1995). However, the results of this study further support the notion that students interpret messages from instructors' response speeds to email messages. Confirming Tatum et al.'s (2018) findings, instructor email response speed has potential to affect student perceptions of instructor credibility. Moreover, student evaluations of instructor email response speed also influence how close students perceive their relationship with their instructor to be, adding to what is known about consequences of instructor email chronemics. The value of instructor-student relationships inside and outside the classroom is indisputable (Frymier \& Houser, 2000;
Nussbaum \& Scott, 1980), and instructor response speeds to student email messages seem to influence the perceived closeness of these important bonds. To some degree, these evaluations seem to also be a function of violated expectations rather than solely the length of time it takes an instructor to respond. If instructors hope to build or maintain credibility in the eyes of students, they should attend to their inboxes accordingly. Further, if instructors seek to develop close relationships with their students, being attentive to student emails may be necessary.

This study represents the first chronemic research to explore microlatencies in email communication. Previous research exploring response speeds in email communication has not investigated the nuances of how small intervals of time (i.e., hours) may affect receiver interpretation of messages. Findings suggest that even within a 24-hour period, there are significant differences in how response speeds are interpreted. For instructors, even a matter of hours could significantly change how students interpret their email response. Initially categorized as an asynchronous form of $\mathrm{CMC}$, these results suggest email usage seems to approach the boundaries of synchronicity (Walther, 1995). Email has evolved from technology that is attended to on occasion (i.e., checking one's physical mailbox) to a form of communication that actively interjects itself into the life of users. While these findings are informative for instructional practitioners and researchers, the exploration of microlatencies represents a significant contribution to $\mathrm{CMC}$ chronemic research as a whole.

\section{Limitations and Future Directions}

The results of this study must be interpreted in light of its shortcomings. First, the experimental nature of the study brings 
about anticipated limitations, as vignettes may never fully capture the true nature of the passage of time or the experience of actual email communication between an instructor and student. Pertinent factors such as class size, course subject, a pre-existing instructorstudent relationship, and the frequency of class meetings were ignored. Further, although offering additional experimental control, the exclusion of metadata (i.e., subject lines, email addresses, timestamps, dates) likely affected the believability of the email exchange and thus the ecological validity of the study. Future studies should seek to explore actual instructor-student email exchanges as they occur in real-time to better account for these factors.

Second, the present methodology eliminates meaningful context surrounding students' chronemic expectations and instead relies on their general expectations and evaluation of an unknown instructor. In reality, every "classroom is unique, thus perceptions of appropriateness and effectiveness of certain behaviors vary from classroom to classroom" (Generous et al., 2015, p. 129). While EVT research does support the notion that individuals hold general expectations towards various groups that inform evaluations (Burgoon \& Walther,1990), students likely have distinctive expectations for each instructor based on past interactions. Additional research is needed to better understand how student response time expectations change over time based on their interactions with a specific instructor.

Third, while novel, this study's method for operationalizing violation valence is limiting. In past research, scholars have relied on single items or brief scales (e.g., Burgoon \& Walther, 1990) to measure participant perceptions of violated expectations. However, the present method assumed violated expectations of participants based on time differentials rather than having participants report their own subjective violation experiences. In this way, the present categorization of participants could lack construct validity. Future research should further scrutinize and evaluate this method of violation operationalization. Similarly, although commonplace is existing EVT research (e.g., Dragojevic et al. 2019), the extent of chronemic violations was ignored in this study, oversimplifying the nuance of EVT. Indeed, not all violations, whether positive or negative, have the same violation extent (Afifi \& Metts, 1998). For example, although both are negative violations, the extent to which an instructor replying one hour late negatively violates a students' chronemic expectations is not the same as an instructor replying 20 hours late. As framed by EVT, extremely negative violations should be evaluated less favorably than minimally negative violations (Burgoon, 2005). As such, researchers could explore if there is an association between the extent of violations, treated as a continuous variable, and students' subsequent evaluations of instructors.

Fourth, expectancy confirmations were not explored in this study. Less is known about how source evaluations resulting from expectancy confirmations compare to those of positive or negative violations. According to EVT, positive violations should produce more favorable evaluations than expectancy confirmations, and negative violations should produce less favorable evaluations than expectancy confirmations (Burgoon, 2015). However, a paucity of research employing EVT actually empirically tests these propositions (e.g., Andersen et al., 1998; Bartholow et al., 2001). Future research should fill this gap by exploring expectancy confirmations in instructor-student email chronemics research. 


\section{Conclusion}

When responding to student emails, how fast is fast enough? As noted by Weinstock (2004), students "live in a world of invisibility and speed. No longer shackled by cables, cords, or wires, [they] move unhindered through invisible streams of data that surround and traverse . . homes, workplaces, [classrooms,] and bodies" (p. 365 ). If instructors hope to elicit positive email response speed evaluations, the question posed above has a unique answer for each student. Being fast enough is not just about responding quickly, but rather, responding more quickly than students expect.

\section{References}

Afifi, W. A., \& Metts, S. (1998). Characteristics and consequences of expectation violations in close relationships. Journal of Social and Personal Relationships, 15(3), 365-392. https://doi. org/10.1177/0265407598153004

Andersen, P. A., Guerrero, L. K., Buller, D. B., \& Jorgensen, P. F. (1998). An empirical comparison of three theories of nonverbal immediacy exchange. Human Communication Research, 24(4), 501-535. https://doi.org/10.1111/j.14682958.1998.tb00429.x

Argon, S. (2003). Creating social presence in online environments. New Directions for Adult and Continuing Education, 2003(100), 57-68. https://doi. org/10.1002/ace.119

Bartholow, B. D., Fabiani, M., Gratton, G., \& Bettencourt, B. A. (2001). A psychophysiological examination of cognitive processing of and affective responses to social expectancy violations. Psychological Science, 12(3), 197-204. https://doi.org/10.1111/1467-9280.00336

Bevan, J. L., Ang, P. C., \& Fearns, J. B. (2014). Being unfriended on Facebook: An application of expectancy violation theory. Computers in Human Behavior, 33, 171-178. https://doi.org/10.1016/ j.chb.2014.01.029

Bolkan, S., \& Holmgren, J. L. (2012). "You are such a great teacher and I hate to bother you but...": Instructors' perceptions of students and their use of e-mail messages with varying politeness strategies. Communication Education, 61(3), 253-270. https://doi.org/10.1080/03 634523.2012.667135

Brooks, C. F., \& Young, S. L. (2016). Exploring communication and course format: Conversation frequency and duration, student motives, and perceived 
teacher approachability for out-ofclass contact. The International Review of Research in Open and Distributed Learning, 17(5), Retrieved from http:// www.irrodl.org/index.php/irrodl/article/ view/2561/3863

Burgoon, J. K. (1993). Interpersonal expectations, expectancy violations, and emotional communication. Journal of Language and Social Psychology, 12(1-2), 30-48. https://doi. org/10.1177/0261927X93121003

Burgoon, J. K. (1995). Cross-cultural and intercultural applications of expectancy violations theory. In R. L. Wiseman (Ed.), Intercultural communication theory (pp. 194-214). Sage.

Burgoon, J. K. (2015). Expectancy violations theory. In C. R. Berger, \& M. E. Roloff (Eds.), The international encyclopedia of interpersonal communication (pp. 1-9). Wiley Blackwell. https://doi. org/10.1002/9781118540190.wbeic102

Burgoon, J. K., \& Hale, J. L. (1988). Nonverbal expectancy violations: Model elaboration and application to immediacy behaviors. Communication Monographs, 55(1), 58-79. https://doi. org/10.1080/03637758809376158

Burgoon, J. K., \& Jones, S. B. (1976). Toward a theory of personal space expectations and their violations. Human Communication Research, 2(2), 131-146. https://doi.org/10.1111/j.1468-2958.1976. tb00706.x

Burgoon, J. K., \& Walther, J. B. (1990). Nonverbal expectancies and the evaluative consequences of violations. Human Communication Research, 17(2), 232-265. https://doi.org/10.1111/j.14682958.1990.tb00232.x

Chang, C. W., Hurst, B., \& McLean, A. (2016). How fast is fast enough? Education students' perceptions of email response time in online courses. Journal of
Educational Technology Development \& Exchange, 9(1), 1-11. https://doi. org/10.18785/jetde.0901.01

Chory, R. M. (2007). Enhancing student perceptions of fairness: The relationship between instructor credibility and classroom justice. Communication Education, 56(1), 89-105. https://doi. org/10.1080/03634520600994300

Claus, C. J., Booth-Butterfield, M., \& Chory, R. M. (2012). The relationship between instructor misbehaviors and student antisocial behavioral alteration techniques: The roles of instructor attractiveness, humor, and relational closeness. Communication Education, 61(2), 161183. https://doi.org/10.1080/03634523.20 11.647922

Conklin, S., \& Dikkers, A. G. (2021). Instructor social presence and connectedness in a quick shift from faceto-face to online instruction. Online Learning, 25(1), 135-150. https://doi. org/10.24059/olj.v25i1.2482

Curtis, A., Lundquist, J., Templer, A., \& Misra J. (2013, October). Eaten by e-mail. American Association of University Professors, Retrieved from https:// www.aaup.org/article/eaten-e-mail\#. WJYm7BsrKUk

Duran, R. L., Kelly, L., \& Keaten, J. A. (2005). College faculty use and perceptions of electronic mail to communicate with students. Communication Quarterly, 53(2), 159-176. https://doi. org/10.1080/01463370500090118

Dragojevic, M., Tatum, N. T., Beck, A. C., \& McAninch, K. (2019). Effects of accent strength expectancy violations on language attitudes. Communication Studies, 70(2), 133-150. https://doi.org/10 $.1080 / 10510974.2018 .1526815$

Finn, A. N., \& Ledbetter, A. M. (2013). Teacher power mediates the effects of technology policies on teacher credibility. 
Communication Education, 62(1), 26-47. https://doi.org/10.1080/03634523.2012.72 5132

Foral, P. A., Turner, P. D., Monaghan, M. S., Walters, R. W., Merkel, J. J., Lipschultz, J. H., \& Lenz, L. L. (2010). Faculty and student expectations and perceptions of e-mail communication in a campus and distance doctor of pharmacy program. American Journal of Pharmaceutical Education, 74(10), 1-11. https://doi. org/10.5688/aj7410191

Frymier, A. B., \& Houser, M. L. (2000). The teacher-student relationship as an interpersonal relationship. Communication Education, 49(3), 207-219. https://doi. org/10.1080/03634520009379209

Frymier, A. B., \& Thompson, C. A. (1992). Perceived teacher affinityseeking in relation to perceived teacher credibility. Communication Education, 41(4), 388-399. https://doi. org/10.1080/03634529209378900

Generous, M. A., Frei, S. S., \& Houser, M. L. (2015). When an instructor swears in class: Functions and targets of instructor swearing from college students' retrospective accounts. Communication Reports, 28(2), 128-140. https://doi.org/10 $.1080 / 08934215.2014 .927518$

Jiang, J. J., Klein, G., \& Carr, C. L. (2002). Measuring information system service quality: SERVQUAL from the other side. MIS Quarterly, 26, 145-166. https://doi. org/10.2307/4132324

Jin, S. A. A. (2012). The virtual malleable self and the virtual identity discrepancy model: Investigative frameworks for virtual possible selves and others in avatar-based identity construction and social interaction. Computers in Human Behavior, 28(6), 216-216. https://doi. org/10.1016/j.chb.2012.06.022

Johnson, D. I. (2012). Swearing by peers in the work setting: Expectancy violation valence, perceptions of message, and perceptions of speaker. Communication Studies, 63(2), 136-151. https://doi.org/10 $.1080 / 10510974.2011 .638411$

Johnson, D. I., \& Lewis, N. (2010). Perceptions of swearing in the work setting: An expectancy violations theory perspective. Communication Reports, 23(2), 106-118. https://doi.org/10.1080/0 8934215.2010 .511401

Johnson, E. J., \& Card, K. (2007). The effects of instructor and student immediacy behaviors in writing improvement and course satisfaction in a web-based undergraduate course. Mountain Rise, 4(2), 1-21. https://doi.org/10.1080/105109 74.2011 .638411

Kalman, Y. M., \& Rafaeli, S. (2011). Online pauses and silence: Chronemic expectancy violations in written computer-mediated communication. Communication Research, 38(1), 54-69. https://doi. org/10.1177/0093650210378229

Kalman, Y. M., Scissors, L. E., Gill, A. J., \& Gergle, D. (2013). Online chronemics convey social information. Computers in Human Behavior, 29(3), 1260-1269. https://doi.org/10.1016/j.chb.2012.12.036

Ledbetter, A. M. (2008). Chronemic cues and sex differences in relational e-mail: Perceiving immediacy and supportive message quality. Social Science Computer Review, 26(4), 466-482. https://doi. org/10.1177/0894439308314812

Ledbetter, A. M., Mazer, J. P., DeGroot, J. M., Meyer, K. R., Mao, Y., \& Swafford, B. (2011). Attitudes toward online social connection and self-disclosure as predictors of Facebook communication and relational closeness. Communication Research, 38(1), 27-53. https://doi. org/10.1177/0093650210365537

Liebman, N., \& Gergle, D. (2016, February). It's (not) simply a matter of time: The relationship between CMC cues and 
interpersonal affinity. In Proceedings of the 19th ACM Conference on ComputerSupported Cooperative Work \& Social Computing (pp. 570-581). ACM.

Martin, J., \& Tatum, N. T. (2017). “Thanks for the quick reply!": Email chronemics and instructor liking. Pennsylvania Communication Annual, 73(1), 50-67.

McCroskey, J. C., \& Teven, J. J. (1999). Goodwill: A reexamination of the construct and its measurement. Communication Monographs, 66(1), 90-103. https://doi. org $/ 10.1080 / 03637759909376464$

McCroskey, J. C., \& Young, T. J. (1981). Ethos and credibility: The construct and its measurement after three decades. Central States Speech Journal, 32(1), 24-34. https://doi. org/10.1080/10510978109368075

McLaughlin, C., \& Vitak, J. (2012). Norm evolution and violation on Facebook. New Media \& Society, 14(2), 299-315. https:// doi.org/10.1177/1461444811412712

Mottet, T. P. (2000). Interactive television instructors' perceptions of students' nonverbal responsiveness and their influence on distance teaching. Communication Education, 49 (2), $146-164$. https://doi. org/10.1080/03634520009379202

Mottet, T. P., Frymier, A. B., \& Beebe, S. A. (2006). Theorizing about instructional communication. In T. P. Mottet, V. P. Richmond, and J. C. McCroskey (Eds.), Handbook of instructional communication: Rhetorical and relational perspectives (pp. 255 -282). Allyn \& Bacon.

Nussbaum, J. F., \& Scott, M. D. (1980). Student learning as a relational outcome of teacher-student interaction. Annals of the International Communication Association, 4(1), 553-564. https://doi.org/10.1080/238 08985.1980.11923824
Pate, A. N., Fleming, L., Jones-Bodie, A., Wagner, J. L., Fleming, J. W., Davis, C., \& Brown, M. A. (2021). Impact of communication method and timeliness on student and faculty perception of professionalism and value. American Journal of Pharmaceutical Education, 85(8), 1-10. https://doi.org/10.5688/ ajpe 8391

Ramirez, A., \& Wang, Z. (2008). When online meets offline: An expectancy violations theory perspective on modality switching. Journal of Communication, 58(1), 2039. https://doi.org/10.1111/j.14602466.2007.00372.x

Reis, H. T., Clark, M. S., \& Holmes, J. G. (2004). Perceived partner responsiveness as an organizing construct in the study of intimacy and closeness. In Handbook of closeness and intimacy (pp. 211-236). Psychology Press.

Ridings, C. M., Gefen, D., \& Arinze, B. (2002). Some antecedents and effects of trust in virtual communities. The Journal of Strategic Information Systems, 11(3-4), 271-295. https://doi.org/10.1016/S09638687(02)00021-5

Schrodt, P. (2003). Students' appraisals of instructors as a function of students' perceptions of instructors' aggressive communication. Communication Education, 52(2), 106-121. https://doi. org/10.1080/03634520302468

Sheer, V. C., \& Fung, T. K. (2007). Can e-mail communication enhance professor-student relationship and student evaluation of professor?: Some empirical evidence. Journal of Educational Computing Research, 37(3), 289-306. https://doi. org/10.2190/EC.37.3.d

Stafford, L., \& Hillyer, J. D. (2012). Information and communication technologies in personal relationships. Review of Communication, 12(4), 290312. https://doi.org/10.1080/15358593.20 


\subsection{1}

Stephens, K. K., Houser, M. L., \& Cowan, R. L. (2009). R u able to meet me: The impact of students' overly casual e-mail messages to instructors. Communication Education, 58(3), 303-326. https://doi. org/10.1080/03634520802582598

Tatum, N. T. (2021). Appropriate humor and confirmation as instructor rapport-building behaviors. Communication Research Reports, 38(4), 241-249. https://doi.org/10 .1080/08824096.2021.1930528.

Tatum, N. T., Martin, J., \& Kemper, B. (2018). Chronemics in instructorstudent e-mail communication: An experimental examination of student evaluations of instructor response speeds. Communication Research Reports, 35(1), 33-41. https://doi.org/10.1080/08824096.2 017.1361396

Teven, J. J. (2001). The relationship among teacher characteristics and perceived caring. Communication Education, 50(2), 159-169. https://doi. org/10.1080/03634520109379241

Teven, J. J., \& McCroskey, J. C. (1997). The relationship of perceived teacher caring with student and teacher evaluation. Communication Education, 46(1), 1-9. https://doi. org/10.1080/03634529709379069

Walther, J. B. (1992). Interpersonal effects in computer-mediated interaction: A relational perspective. Communication Research, 19(1), 52-90. https://doi. org/10.1177/009365092019001003

Walther, J. B. (1994). Anticipated ongoing interaction versus channel effects on relational communication in computer-mediated interaction. Human Communication Research, 20(4), 473-501. https://doi.org/10.1111/j.1468-2958.1994. tb00332.x

Walther, J. B. (1995). Relational aspects of computer-mediated communication:
Experimental observations over time. Organization Science, 6(2), 186-203. https://doi.org/10.1287/orsc.6.2.186

Walther, J. B. (2011). Theories of computermediated communication and interpersonal relations. In M. L. Knapp \& J. A. Daly (Eds.), The SAGE handbook of interpersonal communication (4th ed., pp. 443-479). Sage.

Walther, J. B., \& Tidwell, L. C. (1995). Nonverbal cues in computermediated communication, and the effect of chronemics on relational communication. Journal of Organizational Computing and Electronic Commerce, 5(4), 355-378. https://doi. org/10.1080/10919399509540258

Weinstock, J.A. (2004). Respond now! E-mail, acceleration, and a pedagogy of patience. Pedagogy, 4(3), 365-383. https://doi. org/10.1215/15314200-4-3-365

Young, S., Kelsey, D., \& Lancaster, A. (2011). Predicted outcome value of e-mail communication: Factors that foster professional relational development between students and teachers. Communication Education, 60(4), 371388. https://doi.org/10.1080/03634523.20 11.563388

Zimmerman, A. B., \& Zimmerman, A. B. (2016). The joint impact of management expressed confidence and response timing on auditor professional skepticism in client email inquiries. Managerial Auditing Journal, 31(6/7), 566-588. 


\section{Appendix 1}

Email Vignette Template

Imagine you are a student contacting your instructor via e-mail about an upcoming assignment for a face-to-face course. In order to get some clarification about the assignment, you send the following e-mail:

\section{From: Taylor Jones}

To: Dr. Morrison

Dr. Morrison,

My name is Taylor Jones. I am a student in your COMM 211 Public Speaking Class.

I have a brief question about one of the daily work assignments for this class and need some help with the instructions. Can I stop by your office in the near future to get some clarification?

Please get back to me at your earliest convenience.

Taylor Jones

After sending the above e-mail, you receive the following e-mail response from your instructor \#\#\#\# hours after you sent the initial e-mail:

\section{From: Dr. Morrison}

\section{To: Taylor Jones}

Taylor,

Absolutely. Feel free to stop by my office before or after class this week. If you are unavailable at those times, we can work to make an appointment at a time that works for both of us.

See you in class tomorrow.

Dr. Morrison 